\title{
A Literature Review on China's Pro-poor Tourism from the Perspective of Government, Enterprise and the Poor*
}

\author{
Jin Wang \\ School of History \& Culture (Tourism) \\ Sichuan University \\ Chengdu, P. R. China 610065 \\ School of Tourism \\ Chongqing University of Arts and Sciences \\ Chongqing, P. R. China 402160
}

\begin{abstract}
This research analyzes the literatures indexed in Chinese National Knowledge Infrastructure (CNKI) related to poor alleviation in China pro-poor tourism from 1986 to 2016. Firstly, research shows pro-poor tourism in China can be classified into three stages since 1986 till now as budding stage(1986s-1996s), development stage(1997s-2006s) and active stage (2007s-2016s) according to the number of publications. Secondly, this research points out the conclusion and key views of PPT-related research from the perspective of government, social enterprise and the local poor according to above three stages. Lastly, potential research hotpot in future pro-poor tourism is proposed based on shortage of current related research.
\end{abstract}

\section{Keywords -literature review; pro-poor tourism; China}

\section{INTRODUCTION}

Poverty has been one of 3P problems (Poverty, Population and Pollution) in the long term of human history which indicates it does not only signifies low income but it also means the lack of right to the poor to enjoy a normal live. The essence of poverty is the lost of ability to generate both income and opportunity (Amartya Sen, 1998). Since Anti-poverty has been listed as the top 1 of 8 goals of Millennium Development Goals, researchers in the world began to pay much attention on eradicating extreme poverty and hunger. Pro-poor tourism (PPT) is a special and effective way to eradicate poor and boost economy in China while there is a repeatability between the poor area and abundance of natural tourism resource. Thus, a connection between the poor district and tourism industry has been constructed.

*Funding: This research was supported by China Humanities and Social Sciences of the Chinese Ministry of Education, project of The Community Benefit of Ethnic Minority Village in Sichuan from Perspective of Pro-poor Tourism(16YJC630119), project of Development of Sub-tourist Destination Based on Image Defilation Theory (11XJC630015) and by Chongqing University of Arts and Sciences, project Construction of Tourism Functional Zone in Western China under the Background of Improvement of Industrial Structure (Z2012LY01)

\section{A. The Connotation of Pro-poor Tourism in China}

In China, PPT is leaded and dominated by government which implies that local government plays versatile roles as policy maker, manager, coordinator and investor in the procedure of poor deduction by tourism (Zeng Benxiang, 2006). To implement PPT, the rank and quality of local tourism resource of nature and culture accounts for the basic conditions (Wang Xingshui, 2004). Then, a district as a city, county or village where is judged under national poverty line is usually taken granted as a place of poor relief.

TABLE I. Characteristics of THE PoOR AREA AT NATIONAL LEVEL

\begin{tabular}{|l|l|}
\hline $\mathbf{1 9 8 5 - 1 9 9 2}$ & annual income below 150 yuan \\
\hline $\mathbf{1 9 9 3 - 2 0 0 1}$ & annual income below 400 yuan \\
\hline $\mathbf{2 0 0 2 - 2 0 1 0}$ & Annual income below 700 yuan \\
\hline $\mathbf{2 0 1 1 - 2 0 1 5}$ & Annual income below 1300 yuan \\
\hline
\end{tabular}

As "Table I" shows since the 1985 s, there are four stages can be defined as the targeted poor. The China government has been insisting on putting much effort on alleviating poor and has got great achievement.

Since the poor-stricken area has got general characteristics in China. Such as the first industry plays the most important role in its economy structure while it often locates in remote region far away from downtown but with abundant of natural or cultural tourism resource. Hence, assistant the poor by developing tourism becomes popular and effective in alleviating poverty.

\section{B. The Objective of Pro-poor Tourism in China}

Many research achieve a common view that the purpose to develop PPT lies in helping the poor getting more channels of acquiring economic benefits as well as the chance of development (Li Jia, Zhong Linsheng, Cheng Shengkui, 2009; Qiu Yunmei, 2004). Furthermore, opportunities to be trained as a tourism manager, or tourism operator are vital indexes included in PPT evaluation system 
(Wu Yingxiang, 2010). Additionally, integration and promotion of local industrial chain under the guide of tourism is also regarded as an nonnegligible objective.

\section{METHODOLOGY}

Zeng Benxiang(2006), Wang Dongliang(2010), Liang Kun(2013), Kuang Xuedong(2014), Li Huiqin (2015) have analyzed the literatures related to pro-poor tourism in China and abroad. However, most of them concentrated on the academic articles in 5-10 years. Such as that of Liang Kun, were more concerned with the analysis of related articles between 2003 and 2012 in China. Zeng Benxiang(2006) also have reviewes tourism elimination poverty (TEP) in China and pointed out that it lacked of deep and systematic studies of review on TEP research in a longer period of time, which is the primary concern of this paper.

Chinese National Knowledge Infrastructure (CNKI) is considered as the most authoritative research tools for searching literatures. It is widely used by Chinese scholars as a fundamental research tool. This paper focuses on the recent publications included in CNKI in recent 30 years(1986-2016)through advanced search with main keywords "旅游" (Chinese Character, which means tourism）"扶贫"（Chinese Character which means poor alleviation/reduction) "贫困人口/地区" (Chinese character which means the poor/district) and time period from 1986 to 2016. Finally, 4065 results mainly includes academic articles and dissertations were found that satisified the prerequisites which has been proposed.

\section{RESULTS OF BIBLIOMETRIC ANALYSIS IN 1986S- $2016 \mathrm{~s}$}

\section{A. Brief Introduction of Publications}

TABLE II. BRIEF INTRODUCTION TO PRO-POOR TOURISM OF CHINA IN $1986 \mathrm{~S}-2016 \mathrm{~S}$

\begin{tabular}{|c|c|c|}
\hline $\begin{array}{l}\text { Year and } \\
\text { quantity }\end{array}$ & $\begin{array}{c}\text { Main research } \\
\text { methods }\end{array}$ & Objective of research \\
\hline $\begin{array}{c}\text { 1986- } \\
1996(8)\end{array}$ & $\begin{array}{l}\cdot \text { case study; } \\
\text { - conceptual analysis. }\end{array}$ & $\begin{array}{l}\text { Migrants from Three Gorges } \\
\text { areas,the poor districts in } \\
\text { Guizhou province. }\end{array}$ \\
\hline $\begin{array}{c}1997- \\
2006(497)\end{array}$ & $\begin{array}{l}\text { - casestudy; } \\
\text { ·behavioral research; } \\
\text {-observation; } \\
\text { ·comparison.. }\end{array}$ & $\begin{array}{l}\text { The poverty-stricken area in } \\
\text { western China has been } \\
\text { concerned mostly. }\end{array}$ \\
\hline $\begin{array}{c}\text { 2007- } \\
2016(3560)\end{array}$ & $\begin{array}{l}\text {. case study; } \\
\text { - behavioralresearch; } \\
\text {-observation; } \\
\text { - comparison; } \\
\text {-investigation; } \\
\text {-statistic analysis. }\end{array}$ & $\begin{array}{l}\text { The contiguous poor area in } \\
\text { China,especially the poor } \\
\text { minority area are priority for } \\
\text { research. }\end{array}$ \\
\hline Total & \multicolumn{2}{|l|}{4065} \\
\hline
\end{tabular}

From above "Table II", it is clear that three stages can be deduced in pro-poor tourism (PPT) research of China which are budding stage (1986s-1996s), development stage(1997s2006s) and active stage(2007s-2016s) according to the number of publications.

\section{B. Research Focus}

Generally, it is undisputed that the development of tourism will boost the economy in poor-stricken area which indicates a positive effect on optimizing the industrial structure of the local. The related research focuses mostly on the following: (a) main problems should be solved in poverty reduction through tourism development (Yang Hongying,1998; Deng Zhuren, Chen Daoping,1996; Tian Xizhou etc., 1999; Jin Xiping etc., 2001; Guo Wei etc., 2001; Guo Qingxia, 2003 etc.); (b) The impact of developing tourism in poor stricken area inWestern China.(Cai Xiong,2000; Lin Hong, 2000; Yuan Xiangzhu, 2002 etc.); (c) Financial channels of PPT.(Pan Huanhui, 1999; Zhu Jianmin, 2006 etc.);(d) The relationship between industry development and PPT (Pan Jianmin, 2001; Wang Yimin etc., 2001 etc.)

In fact, the mode applied in PPT is not the equivalent of a normal development of scenic spot since the aim of PPT lies in alleviating poverty rather than developing tourism economy. From the perspective of tourism stakeholders, the government, social enterprises (investors) and the poor are the main participators in PPT, we can classify the research focuses as following "Table III":

TABLE III. PPT RESEARCH IN CHINA

\begin{tabular}{|c|c|}
\hline $\begin{array}{c}\text { Research } \\
\text { perspective }\end{array}$ & $\begin{array}{l}\text { Research subject and } \\
\text { the representative author }\end{array}$ \\
\hline Government & $\begin{array}{l}\text { (1) Policy-making for PPT (Li Yongwen,2002;Zhao } \\
\text { Weibin,2003; ) } \\
\text { (2) Venture Analysis of PPT (Zhao Weibin,2003;) } \\
\text { (3) Sustainable development of PPT (Li Gang,2006;) } \\
\text { (4) Rural tourism and PPT development (Liang } \\
\text { Mingzhu,2004; Guo qingxia, 2005;) } \\
\text { (5) Industry development and PPT (Deng Xiaohai, } \\
\text { 2014; ) } \\
\text { (6 The problem of PPT (Chen Jianping, 2006;) } \\
\text { (DThe strategy of PPT (Wu Yanji,2004;Yang Yaying, } \\
\text { 2005;) } \\
\text { (8)PT mode in the area of minority (Hu Xiru, 2003; } \\
\text { Chen Jianping, 2006;) } \\
\text { (9Empirical analysis of PPT(Liu Baowei, 2004;) } \\
\text { D PPT in developed area.(Liu Huiyu,2002; Yang } \\
\text { Min,2003;) } \\
\text { D Review research of PPT.(Zhen Benfa,1999;Liu } \\
\text { Yi,2004;Wu Yanji,2004; Zeng Benxiang,2006.) }\end{array}$ \\
\hline $\begin{array}{l}\text { Social } \\
\text { enterprises }\end{array}$ & $\begin{array}{l}\text { C2Business operation in scenic spot in poor-stricken } \\
\text { area (Zhang Wei, 2005.) }\end{array}$ \\
\hline The poor & $\begin{array}{l}\text { BCommunity involvement in PPT (Xie Zedong, Ma } \\
\text { Zunping, Ru me,2015; Li Yanqin,2015;) } \\
\text { CLLegal protection mechanism of the poor community } \\
\text { (Li Xiaoqin, 2016) } \\
\text { B Channels for community benefit in PPT (Hong } \\
\text { Jing,2009;) }\end{array}$ \\
\hline
\end{tabular}

\section{Highlight of Research}

1) From Perspective of Government's Responsibility. As noted above, research perspective from government accounts for a large part of the academic articles. Most authors (Liang Xiangming,2001; Ji Dan,2007; Jiang Shudong,2014; Long Jiaxi,2016 etc..) argued that local government palys as a supervisor and organizer during the 
whole process of PPT that implies it has the responsibility to make series of effective measures of anti-poverty used for guiding the enterpriese, investors and the poor involved in PPT. Most research have suggested that the mission of government in PPT mainly lies in four aspects: (a) Making PPT development strategy(Wang Ying,2005; Liao Zhaoguang,2007;Liu Rui,2010.); (b) Guiding social enterpriese involved positively and attracting business;(Yang Yaying, 2005; Zhao Lili, 2009.); (c) Formulating tourism planning scientifically ; (Deng Xiaoyan, 2002; Zhao Lili,2003;Wang Chengwu,2010.); ( d ) Infrastructure construction (Lu Shiju,2001;Bao Junjun,2015). Besides, to establish the investment and fundraising system in the process of PPT is also regarded as the important task for government which usually includs buliding special fund for PPT or encouraging tourism company to found stockholding system.It is still strongly signifies that government should give support with finance and future-development for the enterprises who attend PPT. However,with the contradiction between tourism and ecology,strict examination and approval to tourism projects is also considered as government's assignment to preside PPT.

2) From perspective of social enterprises. A few number of studies were found in PPT research from perspective of enterprises or individual investor before 2006s. Among these studies, the focus of research lies in the inharmony between management and operation of scenic spot. Since in China, tourism-related administrative department is not only the tourism bureau, but also the construction bureau, the forestry bureau, the fishery agency, the environment protection bereau and so forth. However, there is a neckbottle between the ownership and property right of scenic spot resource that means the ownership of natural resource belongs to the nation which is state-owned while the operator maybe an enterprise or an investor that may bring a lots of problems on management and operation of a scenic spot.

Li Rui (2012) analyzed the PPT mode of stakeholders in PPT of a scenic spot named Chong Dugou in Henan province of China based on stakeholder theory.

TABLE IV. BENEFIT AND EXPENDITURE OF THE STAKEHOLDERS IN PPT in Chong Dugou SCEnIC Spot in He NAN PROvince, China

\begin{tabular}{|c|c|c|}
\hline source of revenue & beneficiary & Item of expenditure \\
\hline $\begin{array}{l}\text { - entrance ticket } \\
\text {-parking fee } \\
\text {-rent for } \\
\text { entertainment facility }\end{array}$ & $\leftarrow$ tourismenterprise $\rightarrow$ & $\begin{array}{l}\text { Infrastructure; marketing; } \\
\text { enviromental protection; } \\
\text { tourism planning; } \\
\text { salary; transfer fee etc. }\end{array}$ \\
\hline $\begin{array}{l}\text {-accommodation, bev- } \\
\text { erage for homestay } \\
\text {-rent for land }\end{array}$ & $\longleftarrow$ the poor & $\begin{array}{l}\text { house decoration } \\
\text { daily expense etc. }\end{array}$ \\
\hline $\begin{array}{l}\operatorname{tax} \\
\text { transfer fee }\end{array}$ & - government & $\begin{array}{l}\text { education and training; } \\
\text { support for enterprise; } \\
\text { Welfare etc. }\end{array}$ \\
\hline
\end{tabular}

When the private capital invested into tourism project in poverty-stricken area, the investors expect economic benefits in PPT development. Thus, how to make a balance between the poverty reduction and social enterprises' benefits then build a relatively stable cooperation is still a hot topic in PPT research.

3) From Perspective of the Poor. Comparing to above, the research of PPT from perspective of the poor is fewer and fresh for there is less than 100 relative articles indexed by CNKI a very popular academic database in China. Li Juxia and Lin Xia (2000) proposed that have the local residents involved in tourism industry by encouraging them opening homestay. Chen Xiuqiong and Huang Jinhuo (2003) pointed out the personal condition of the poor cannot be neglected. Such as the personal education background and social experience. Furthermore, minority poor-stricken area plays a vital role in PPT research for their unique custom and lifestyle. In China, generally, three strategies of PPT related to ethnic area have been suggested which are government-oriented model, tourism resource-oriented model and pro-poor tourism model (Wu Yingxiang, 2010). Li Jing(2006) analyzed the tourism community involvement about the nationality of Bai, Hui and Yi in Yunnan province which reveals the factors influence directly the local involvement in PPT. Such as their educational background, economic level as well as family labor force can result in inequality participation in tourism industry. Because of that, it bring most benefits for a few poor people as most of the poor may lost opportunities for poor reduction and face the problem of ecologic environment. Some scholars argues that the results of PPT have been over estimated (Liu Xiangming, Yang Zhimin, 2002; Bolwell D, Weinz W, 2008) for lots of tourism revenue belongs to investors of tourism enterprises and it is very seasonal for hiring the local attending in tourism service (Guo Shu, 2015). Generally, it indicates that the success of PPT lies in building channel of benefits from tourism for the poor residents and keep getting out of poor.

\section{DISCUSSION}

\section{A. Does community involvement mean the poor participation?}

Undoubtedly, community is a broad conception. But a mutual view shows that a community indicates many social groups or organizations stay in the same area then they have similarity with lifestyle, culture customs and social communication. It can be deduced that a community which is evaluated as a poor village or county includes kinds of social members as tourism investors or local governments except for the poor. So that it reveals a research perspective: the poor may be a component of poverty community than the whole.

\section{B. How does make industrial structure optimized under the guide of PPT?}

To most tourism destination, tourism is seasonal while it often experiences the period of growing, developing and 
declining. How to guarantee the poor getting benefits in slack season is a critical indicator for PPT performance evaluation. Some scholars pointed out that only having industrial structure optimized by tourism can solve the problem of industry. For some poor districts in China where are implementing poverty reduction by developing tourism, the pro-poor performance is not effective because the local industry is still underdeveloped with incomplete industry chain. Therefore, the optimization and integration of local industry chain by tourism indicates a critical research direction in PPT.

\section{How to keep balance among PPT stakeholders?}

PPT is a government-oriented program. Generally, regulations construction, policy making, fund collecting and institutional design are regarded as main functions of government in PPT since local government plays a vital role in market intervention and directing tourism projects. In fact, the relationship among power, responsibility and benefit among stakeholders in PPT is a problem of game equilibrium that signifies every stakeholder wants to achieve the maximum benefit. Therefore, PPT cannot match with charity which means the benefit models for village, government as well as government are need to be considered. Only all the stakeholders are getting beneficial, can PPT works smoothly. The win-win mechanism has to be constructed and designed by government. In consequence, the balance of benefitgetting between stakeholders under the supervision and guidance of local government is a current research bottleneck which will become an important research direction in the future.

\section{REFERENCES}

[1] Cai Xiong, Lian Yi, Chen Daoping, Bai Ding, Lan Xiongxian. Multiplier and strategy for pro-poor tourism [J]. Social Scientist, 1997(3):4-16.

[2] Deng Zhuren, Chen Daoping. Problems to be solved in pro-poor tourism [J]. Social Scientist, 1998(02):46-54.

[3] Jonathan Mograbi, Christian M.Rogerson. Maximising the Local ProPoor Impacts of Dive Tourism: Sodwana Bay, South Africa[J]. Urban Forum,2007,(2):85-104.

[4] Li Rui,Huang Huiling, Liu Jing. Pattern of Anti-poverty and Development of Scenic Spot of Mountains Tourism:Based on the Field Survey Report about Chongdugou Scenic Spot [J]. Area Research and Development. 2012.02(31):94-98.

[5] Li Jia, Zhong Linsheng, Cheng Shengkui. Study on residents' perception and participational Behavior on the effect of povertyelimination by tourism in ethnic poverty-sticken Areas[J]. Tourism tribune, 2009(08):71-76.

[6] Pan Huanhui. Research on financial channel of pro-poor tourism [J]. Academic Journal of Gui Lin Tourism University, 1999(10): 39-40.

[7] Wu Yingxiang. Minority evolvement in pro-poor tourism[D]. Yun Nan university, 2010.

[8] Yang Zhenzhi, Ma Zhinuan, Chen Jin. On the property rights of scenery resources and their juristical implementing form[J]. Tourism tribune, 2002(4):39-44.

[9] Zhou Xinhong. Key problem on pro-poor tourism [J]. Tourism Tribune, 2002(1).17-21.

[10] Zhu Jianmin. Financial condition and support of pro-poor tourism in mountainous area of Guang Dong $[\mathrm{J}]$. Agricultural Economy, 2006(4):27-28. 